\title{
Some Major Challenges Faced by Civil Engineering Professionals in the Execution of their Profession and the impact of the challenges to the Environment, Society and Economy of Developing Countries
}

\author{
Franklin Ngosong Tougwa* \\ University of Salford, UK
}

*Corresponding author: Franklin Ngosong Tougwa, University of Salford, UK.

Received Date: May 12, 2020

Published Date: May 28, 2020

\begin{abstract}
Civil Engineering is that part of engineering that deals with the application of mathematical and scientific knowledge to improve infrastructures like bridges, dams, buildings, roads, railways and dams and common utilities to help improve human lives and our society. The civil engineering profession involves a lot of sub- disciplines and deals with the design, construction, and maintenance of the built environment. Civil engineers have that social responsibility to properly maintain and adapt structures that we depend on in our daily life and are also involve in making sure the infrastructures are adapted to meet natural disaster, population growth and climate change challenges. They have that responsibility to find and implement solutions to complex problems. However, these engineers face many challenges in executing their duties or carrying on their responsibilities effectively. These challenges have a lot of impact in our society, our environment and the economy of every nation. A literature review of some of these challenges and their impacts to society, environment and the economy are looked upon in this paper.
\end{abstract}

Keywords: Civil engineering; Engineers; Challenges; Infrastructures; Construction; Development; Environment; Developing Countries; Government; Community; Sustainable; Safety; Management; Africa; Cameroon; Social; Political and Economic

\section{Introduction}

Engineering is the application of scientific and mathematical principles, experience, common sense and judgement to practical purposes of the design, analysis and operation of structures, machines and systems. As indicated by Albert Einstein, "Scientist investigate that which already is. Engineers create that which has never been". As define by the Accredited Board for Engineering and Technology (ABET) [1], Engineering is "the profession in which knowledge of the mathematical and natural sciences gained by study, experience, and practices applied with judgement to develop ways to utilise, economically, the materials and forces of nature for the benefit of mankind". Engineers are concerned with the application of mathematics, ingenuity and scientific knowledge to develop solutions for technical problems. Civil Engineering is that part of engineering that deals with the application of mathematical and scientific knowledge to improve infrastructures like bridges, dams, buildings, roads, railways and dams and common utilities to help improve human lives and our society. These improvements are done while ensuring that structures and utilities are safe, they should also be environmentally and economical good. The civil engineering profession deals with the design, construction, and maintenance of the built environment. Civil engineering is a big profession that involves a range of different sub-disciplines or specialisations. These include; construction engineering, structural engineering, water resources engineering, geotechnical engineering, transportation engineering, municipal or urban engineering, environmental engineering, materials engineering, 
coastal engineering, architectural engineering and surveying. Civil engineers don't only have that social responsibility to properly maintain and adapt structures that we depend on in our daily life, they are also involve in making sure the infrastructures are adapted to meet natural disaster, population growth and climate change challenges. They have that responsibility to find and implement solutions to complex problems. However, these engineers faces many challenges in executing their duties or carrying on their responsibilities effectively. These challenges have a lot of impact in our society, our environment and the economy of every nation. A literature review of some of these challenges and their impacts to society, environment and the economy are looked upon in this paper.

\section{Some Major Civil Engineering Challenges}

The Cambridge dictionary defines challenge as, "the situation of being faced with something that needs great mental or physical effort in order to be done successfully and therefore tests a person's ability". Due to the pivotal role civil engineering plays in the development and improvement of societies, Becerik-Gerber et al. [2] described its endeavours as complex and diverse undertakings that tackle nonstandard challenges.

\section{Sustainable construction}

One of the major challenges faced in civil engineering in the developing countries is that of sustainability in construction [3]. This assertion is further confirmed by Adebayo [4] who says enough attention has not been given to sustainable construction in Africa. As asserted by Hill and Bowen [5], the use of the term sustainable construction was to describe the role of the construction industry in the attainment of sustainability. While Adebayo [4] says many nations have understood sustainable construction as the way the building industry attempt in achieving sustainable construction. Dania et al. [6] regards sustainable construction as the construction sector's response to enacting sustainable development. During the International Council for Research and Innovation in Building and Construction (CIB), the researchers agree on the need to have a common agenda on Sustainable Construction that is internationally binding. This was published in its Agenda 21 on Sustainable Construction in 1999. This conclusion was arrived at after an extensive collaboration research process since it was realised that the role played by the construction industry in sustainable development of human settlements is a major one [3]. According to Du Plessis [3], the intention of the CIB Agenda 21 was to serve as a global intermediary between the International and national or regional Agendas for built environment and construction sector with its main objectives to create a general framework and terminology that will add value to the different Agendas and provide a source document for defining research and development activities which are related to sustainable construction. Du Plessis [3] argue that the approach taken by the developed nations to create a sustainable built environment is quite different from the approach to be taken by the developing countries as it is still not very clear and understood. Adebayo [4] supported Du Plessis's argument by saying that sustainable construction has not been given great attention in some developing countries or regions like Africa. Adebayo (2002) stressed that there exist some conflict between theory and practice and there is total misconception about sustainable construction in Africa when compared to developed nations.

Taylor and Norval [7] condemn the fact that construction activities in Africa have been designed following the experience of the developed countries, a practice which they said have created serious issue around construction activities in Africa. Ofori [8] asserted that the perspective of developing countries were not captured when certain framework for sustainable construction were designed and therefore, the framework might not be appropriate to apply to the case of the developing nations. The direct application of experience gathered from the developed world to the developing nations like the African countries has not worked out as the priorities and national circumstances of the African nations are not the same with those of the developed countries. Therefore the definition of sustainable development and construction within the African context need to be redefined as adviced by Taylor and Norval [7]. According to Du Plessis [9], the concept of sustainable development is still an evolving one that depends on how its implementation is carried out on the development at both regional and local approaches and solutions. Due to the difference in definition, approaches and solutions between the developed and developing nations, there is need for the creation of an international agenda for sustainable building that recognises these local and regional differences (ibid). Adebayo [4] raised doubt if sustainable construction can be successfully achieved without having a good understanding of what development is all about. He therefore argued that there must be a proper understanding of the social, political and economic atmosphere and the developmental issues of a particular place before talking about sustainable construction in the that area. He further advocate that when all the issues raised are better understood, sustainable construction then becomes are integral part of sustainable development. Adebayo cited the wars, conflicts and pandemic diseases as examples of practical issues that have put the issue of sustainable construction into debate when it is brought to the table for discussion and makes the issue of sustainable construction in Africa to be seen differently from the way it is seen in the developed world. As part of the recognition of the local and regional differences, Du Plessis [9] advice that there is need to organise a number of regional sustainable building conferences with the development of regional sustainable action plans for sustainable building and sustainable construction in Africa being at the fore. He further states that "The key issue is the establishment of a solid knowledge foundation for Africa that 
will equip the public, professionals, development agencies and governments with accurate and relevant knowledge generated within the framework of the continent's social needs, its cultures and its biophysical environment to guide their decisions and actions towards establishing a sustainable built environment."

Czarnecki et al. [10] reminds us that sustainable development is one of the leading ideas about civilization. As asserted by Kemp et al. [11], many countries have made some strides is achieving sustainable development but are still faced with the challenges of using the right approach. Due to the debate on the application of the concept of sustainable development in developing nations like the African countries, some definitions has been reviewed by Adebayo [4] to see how applicable they are in Africa or if they have been successfully achieved. While the Brundtland Report, WCED [12] defines sustainable development as "development that meets the needs of the present without compromising that ability of future generations to meet their own needs", the International Council for Local Environment Initiatives-ICLEI [13] in its local Agenda 21 planning guide defines it as " development that delivers basic environmental, social and economic services to all residences of a community without threatening the viability of natural, built and social systems upon which the delivery of those systems depends". The European Union [14], in the Treaty of Amsterdam of 1997 on its part defines sustainable development as development that "determine to promote economic and social progress for their peoples, takinginto account the principle of sustainable development and within the context of the accomplishment of the internal market and of reinforced cohesion and environment protection, and to implement policies ensuring that advances in economic integration are accompanied by parallel progress in other fields". Due to the paralysed economy in developing countries, especially African countries as a result of war, heavy debts awaiting the future generation to pay and difficulties in responding to its present and future needs, Adebayo argues that the WCED [12] definition of sustainable development may be applied to the developed world but not to the developing nations like African countries. Adebayo also disagree with the ICLEI [13] definition in the context of the developing nations as he argues that there is total disregard of the natural built environment on construction sites when African government implement government policies. He added that there exist no more socio-cultural dynamics due to its destruction in the implementation of project. While Adebayo criticise or argues the applicability of the definitions of WCED [12] and ICLEI [13] in the African context, he sees the definition of the European Union in the Amsterdam Treaty of 1997 as more favourable within the African context or region as it embraces the integrated development concept within the African context. An approach which professionals, policy makers, development theorist and practitioners have long encouraged as they see it as an approach that engulf sustainability in all aspects. Following this approach, sustainable construction serves as a means through which the construction industry can achieve sustainable development in its entirety, which consequently allows sustainable construction to be driven from the development realm [4]. In Agenda 2001 for construction in developing countries (SCDC), sustainable construction was defined as "a holistic process aiming to restore and maintain harmony between the natural built environments and create settlements that affirm human dignity and encourage economic equity" [15] (Figure 1).

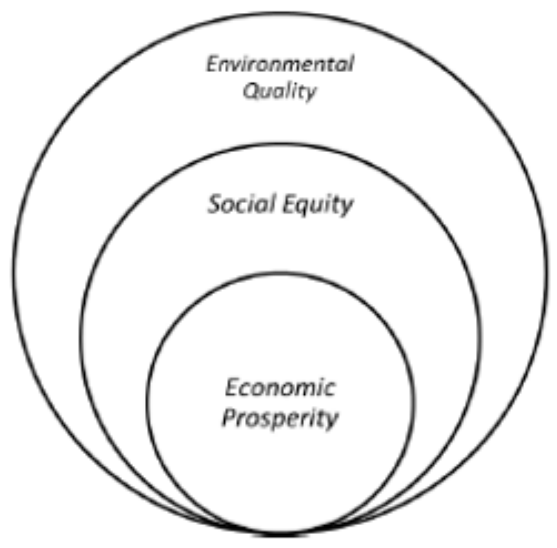

Figure 1: The triple bottom line of Sustainability. Adapted from Dania et al., (2013).

The concept of sustainable construction involves a wider range of concern and pose a lot of challenges and complexities. Due to such challenges and complexities, Dania et al. [6] asserted that sustainable construction involves solving conflicting issues that exit between competing goals and at same time pursue environmental quality, social equity and economic prosperity. They concluded by advising that, the construction industry needs to advance its processes of creating the built environment as it is an important 
aspect in the debate of sustainability. As per the recommendations of Oyebode [16], in order to effectively evaluate Infrastructures for Economy and Sustainable Construction, government should make sure standard and policies that relates to infrastructure development are well addressed and handled in a holistic manner. Again contracts should be effectively evaluated and good consulting and construction services should be put in place to properly implement the projects. According to Becerik-Gerber et al. [2], an expert task forced assembled by the ASCE TCCIT (Technical Council on Computing and Information Technology) Data Sensing and Analysis (DSA) Committee identified nine major challenges that are currently faced by the civil engineering professionals. These major challenges are

1. The improvement of safety on construction site

2. Proper management of groundwater

3. The monitoring and improvement of poor and degrading infrastructure

4. The reduction of soil erosion

5. Reducing traffic congestion

6. Disaster improvement management through infrastructure resilience

7. The Estimation of sea levels

8. The improvement of energy efficiency in building

9. The improvement of construction productivity

The first three challenges listed above will be discussed in this paper with their societal economic and environmental impacts to the community.

\section{The improvement of safety on construction site}

Safety on construction site is the avoidance and protection of workers from having, injuries and fatal accidents which might result to death. The civil engineering sector is one of the world's largest sector with its numerous construction, maintenance and demolition works. While statistics from developed nations shows that the rate at which construction workers die as a result of fatal accidents triple or quadruple those workers in other sectors, the death rate of construction workers in developing nations is suggested to be 3 to 6 times higher than those of developed industrialised nations [17]. In their line of duty, construction workers are exposed to hazards including but not limited to asbestos, harsh weather conditions, manual handling of heavy loads, heavy noise, falls from height, dust emission, struck by equipment, hands arm vibration from tools, electrocution and just to mention a few. Civil Engineering professionals and other professional organisations are faced with the challenge of putting in place firm rules and regulations to be respected by the workers so that the rate of fatal injuries that result to the death of the workers can be reduced. They are bound to educate the workers to understand that their performance is partly dependent on their safety. While the studies of organization safety, cultural and post-accident investigations in developed nations help these professionals to be able to put in place such safety rules and regulations, those of developing nations like Cameroon find it difficult because post-accident investigation is hardly done and thus data of such accidents are hardly kept for future use. While Du Plessis [3] postulated that developing countries lack accurate data on which they can base their decisions on and establish and implement safety programmes like in developed countries, Awwad et al. [18] argues that though health and safety programmes are still at their infancy stage in some developing countries, some developing countries have these programmes in place but fail to implement them properly. These accidents and or death on construction sites impact the economy as they can lead to higher cost of insurance, higher premium to compensate the workers or their families and loss of some workdays. The company might incur most cost on training new workers to replace the injured worker or the one who is death, there will be damages to the project as productivity will be lost [19]. While the societal impact of such accidents or injuries to the company might lead to loss of public confidence to the company, decrease in the morale's of other workers and loss of customer's satisfaction, this can also lead to depression to some affected family members and loss of societal welfare that might consequently affect the quality of life. As asserted by Becerik-Gerber et al. [2], there are hidden costs which are incurred indirectly because of environment impact for the wider community despite the clean-up and management of some accidents related to construction such as spill of hazardous substances and fire. These cost are neither quantified nor well understood (ibid).

\section{Proper management of groundwater}

Since 1950, the use of groundwater has been on a constant rise as a result of increase in population growth and economic developing, thus putting more pressure on the proper management of this natural resource. The sustainability of the welfare gains groundwater development has created is a major challenge face by the world today. While in the industrialised world some advanced experiential knowledge has been developed to properly manage groundwater in various uses and context, the application of this knowledge intelligently in the proper management of groundwater is a big challenge in Asian and African countries today where the increasing use of groundwater for irrigation to support livelihoods has become a threat to groundwater itself [20]. The use of pump wells for groundwater development for municipal, industrial and agricultural supplies has been on the rise since 1950. About 750-800 Km3 of groundwater is used annually in the world [21]. The excessive use of this groundwater in many places has led to groundwater depletion in those places, thus causing damage to 
aquatic ecosystem, decrease in well yields, poor water quality, increase in pumping cost and increase in subsided land [22]. Based on the predictions of climate change and some concerns for aquifer systems and groundwater goods and services which are associated to the systems, Knüppe [23] predicted that there will be further stress on water. The groundwater governance regime of most developing countries don't have the capacity to assure sustainable resource regulation and allocation in an effective manner. According to Knüppe [23], uncertainties such as socio-economic growth, poor protection, and poor governance structure affecting resource use, global climate change, poor regulation and poor implementation of alternative strategies needed to attain sustainable management are some of the issues that are hindering the management of groundwater. Calow et al. [24] argued that predictable variations in groundwater drought vulnerability are scarcely planned for or acted upon. In an effort to identify the challenges that affects the development of an adaptive and sustainable system for groundwater management and the successful implementation of water legislation in South Africa, Knüppe [23] conducted a qualitative assessment of interviews with some South African experts where results shows that, the neglect of ecosystems and the associated goods and service; undervaluation of groundwater importance and significance; the centralisation of power; and the need for expertise and information at all scales are the four major challenges. Economically, the depletion of ground water can lead to increase in cost due to an increase in the lifting distance and more energy required for pumping that will serve as more burden to end users. There will equally be increase in state budget for wastewater treatment. The social impact of poor management of groundwater cannot be over-emphasise as our daily lives greatly depend on groundwater for cooking, drinking, cleaning etc. A continues decrease in groundwater will pose an increasing issue on our daily lives. The contamination of underground water pose great risk to groundwater quality. If not well managed, toxins or contaminants in underground water can endanger the lives of aquatic plants and animals and the underground ecosystem, thus causing great impact to the environment. While considering the complex system linkages between political, hydrogeological, environmental and socio-economic domains, Knüppe [23] assumes that an adaptive water management is a suitable approach for good groundwater resources governance. The development of supporting principles, such as cooperation tools, networks for participation and information that can enable the implementation of adaptive water management approaches that can lead to institutional change in the groundwater management are suitable means to tackle the groundwater management challenges.

\section{The monitoring and improvement of poor and degrading infrastructure}

As stated by Becerik-Gerber et al. [2], infrastructure is the combination of critical facilities and fundamental systems that support a community, region, or country. This includes transportation systems, dams, and schools, underground lifelines (e.g. water, telecommunication conduits, sewage, and electricity). There is the fast degrading rate of infrastructures in developing countries in Africa like Cameroon which needs some attention and investment in their improvement. In order to get accurate data on the state or health of the infrastructures to make an informed decision on what to do or measures to take for its improvement or rehabilitation, there is need for appropriate health monitoring of the infrastructures. There is a need for the Civil Engineering community to have accurate methods of global displacement measurement for use in construction and monitoring the health of infrastructures [25]. There is the need to consider the structure performance and the accrued cost of the entire life cycle to effectively carry out maintenance and management of civil infrastructure in a cost-effective manner [26]. Frangopol and Liu express concerns on how only the life-cycle cost minimization are considered when developing most maintenance and management systems that exist. They believe this single maintenance and management solutions does not yield satisfactory structure performance for a long term. Frangopol and Liu also express frustration over the fact that the performance of structure is usually described by the visual inspection-based structure condition states. There have not been adequate consideration on actual safety level of the structure at time when decisions to determine maintenance management are being taken (ibid). A large number of civil structures in Africa in general and Cameroon in particular have been designed and constructed according to outdated codes of practice. The age of the structures and actual performance of the construction materials affect the overall behaviour of the existing buildings to a great extent. This is also the case with many African countries, where many existing structures no more function adequately due to their age and some structural deficiencies. This makes structural assessment and rehabilitation to become a big challenge in urban management and planning. There is need for evaluation and enhancement of structural safety of already existing structures against earthquakes that results to serious damages and structural collapse [27]. A large part of Fako Division in the South West Region of Cameroon are exposed to medium/high seismic risk due to the presence of Mount Cameroon in Buea. This call for the need to put in place effective measures that could help protect constructions at risk and to mitigate injury and death that might results from seismic events, as those suffered by the population and structures around Mount Cameroon in 1999 and 2000 when the mounted erupted. According to Rainieri et al. [27], the first step in putting such effective measures in place is to increase the knowledge about the structural behaviour of existing structures by providing guidelines which define measures to protect them and decrease the probability of structural damages. While several large research projects have been initiated in the field of civil engineering in developed countries to help in the continuous monitoring of relevant parameters and performance of 
such structures [27], similar studies are hard to find in Africa in general and Cameroon in particular. This pose a serious challenge in developing an effective Structure Health Monitoring system of civil structures in the earthquake prone region of Buea and its nearby vicinities. As opined by Rainieri et al. [27], the protection of civil structures from seismic actions can be achieved by adopting modern design guidelines for new structures and guidelines to recover and restructure the already existing structures. Advanced Structural Health Monitoring (SHM) and Seismic Early Warning (SEW) systems can be used in the assessment of structural performance of existing structures and evaluate their vulnerability and the subsequent interventions required for the structural rehabilitation. The advancement of Information and Communication Technology in developed nations allow for real-time monitoring of structures. These advanced systems and technologies are hardly found in most developing nations. Even if found, they suffer some setbacks in terms of design, installation, the maintenance of cables and some sophisticated electronic components. These measuring and computational devices needs constant power supply. This is a very big challenge in countries like Cameroon and Nigeria where electric power supply is hardly ever stable.

Most of the African countries still practices structural health monitoring just by visual inspection of the infrastructures. This practice in subjective and time consuming as defects are found and assess visually or manually by use of digital cameras to get photographs. The interruption of certain services (e.g. water mains, electricity lines etc.) is another challenge faced during inspections. In a country like Cameroon, the inspectors or technicians at times find it very difficult or almost impossible to accurately locate the infrastructure lines that have been buried long ago. This visual or manual inspection or health monitoring of infrastructures does not provide accurate data or information about the state or health of the infrastructure, thus making it difficult to make informed decision, thus posing a big civil engineering challenge. Economic impact of these challenges are enormous as the aging infrastructures need huge sums of money for their improvement and causes significant economic losses. The need for monitory the health of infrastructure cannot be over emphasize as Salim and Zhu says this can provide real-time updates on their condition and thus supports preventive planning and lessens their inefficiencies and associated failures. The failure of certain infrastructure systems maybe very dangerous to the environment and their impact can be felt for long period of time. For example, a failure on the oil pipeline that transport crude oil from the Bakassi peninsula to Limbe in Cameroon, will result to oil spill into the Gulf of Guinea that will lead to destruction of aquatic lives. The explosion of a natural gas pipeline due to failure will cause so much societal impact as it may cause several deaths. Many buildings (both public and private) has collapsed in the recent past in Cameroon that has resulted to many deaths, idem with road accidents due to poor roads infrastructure in the country. The challenge of identifying the exact location of buried infrastructures may result to the cutting of some essential services that may put the safety of the entire public at serious risk.

\section{Conclusion}

The fast growing population in the developing nations call for more infrastructures to be put in place. There is need for maintaining the already existing ones, which are degrading. This is the duty of the civil engineering professionals but they are face with a lot of challenges. The problem of sustainable construction, improvement construction site safety, proper management of groundwater and the monitoring and improvement of poor and degrading infrastructure are seen as some of the major challenges. While those in the developed nations have done a lot of advance research and put strict regulations to manage those challenges, much is still to be done in the developing nations. Research and experience from the developed nations cannot directly be translated and applied to the developing nations to handle these challenges as these countries don't have same environmental, economic and societal conditions. These challenges negatively impact the society, economy and environment of these countries. Advance research and the collection of appropriate data need to be done so informed decision can be made to help put in place strict and appropriate regulations by the developing countries and good governance structures to ensure strict application of the regulations. These challenges have negative impacts on the society, environment and economy of those developing countries like Cameroon.

\section{Acknowledgment}

None.

\section{Conflict of Interest}

No conflict of interest.

\section{References}

1. Accredited Board for Engineering and Technology (ABET) (1986) 1985 Annual Report. New York, USA.

2. Becerik-Gerber B, Siddiqui M, Brilakis I, El-Anwar O, El-Gohary N, et al. (2014) Civil Engineering Grand Challenges: Opportunities for Data Sensing, Information Analysis, and Knowledge Discovery, Journal of Computing in Civil. Engineering 28(4): 1-13.

3. Du Plessis C (2001) Agenda 21 for Sustainable Construction in Developing Countries-First Discussion Document. CSIR, Pretoria and CIB, Rotterdam.

4. Adebayo AA (2002) Sustainable Construction in Africa. Agenda 21 for Sustainable construction in Developing Countries. Africa Position Paper.

5. Hill RC, Bowen PA (1997) Sustainable construction: principles and a framework for attainment. Construction Management and Economics 15: 23-239.

6. Dania AA, Larsen GD, Yao R (2013) Mainstreaming Sustainable Construction: Case Studies of An Indigenous And Multinational Firm In Nigeria. Working Paper proceedings. Engineering Project Organization Conference. Devil's Thumb Ranch, Colorado. 
7. Taylor RG, Norval GHM (1994) Developing Appropriate Procurement Systems for Developing Communities, CIB W92 Symposium, University of Hong Kong, Hong Kong, CIB Publication No. 175.

8. Ofori G (1998) Sustainable construction; principles and a framework for attainment - comment. Construction Management and Economics 16 141-145.

9. Du Plessis C (2005) Action for sustainability: preparing an African plan for sustainable building and construction, Building Research \& Information 33(5): 405-415.

10. Czarnecki L, Kapron M, Van Gemert D (2010) Sustainable Construction: Challenges, Contribution of Polymers Researches Arena. Second International Conference on Sustainable Construction Materials and Technologies. Università Politecnica delle Marche, Ancona, Italy.

11. Kemp R, Parto S, Gibson RB (2005) Governance for sustainable development: moving from theory to practice. International Journal for Sustainable Development 8: 12-30.

12. WCED (1987) Our common future. The report of the World Commission on Environment and Development, Oxford: Oxford University Press.

13. ICLEI (1996) The Local Agenda 21 Planning Guide - An introduction to sustainable development planning. Toronto: The International Council for Local Environmental Initiatives, The International Development Research Centre, The United Nations Environment Programme.

14. European Union (1997) Treaty of Amsterdam .Treaty of Amsterdam amending the Treaty on European Union, the Treaties establishing the European Communities and certain related acts, signed in Amsterdam. Luxembourg: Office for Official Publications of the European Communities, ISBN 92-828-1652-4.

15. Du Plessis C (2007) A strategic framework for sustainable construction in developing countries. Construction Management Economic 25 (1): 67-76.

16. Oyebode 0J (2018) Evaluation of civil engineering infrastructures for Economy and sustainable construction in Nigeria. Proceedings of the 16th International Conference and Annual General Meeting. Nigerian Institute of Civil Engineers (NICE).

17. Umar T, Wamuziri SC (2016a) A review of construction safety, challenges and opportunities-Oman perspective. In: Sandanayake YG, Karunasena GI and Ramachandra T (eds.) Proceedings of 5th World Construction Symposium 2016 University of Moratuwa, Colombo, Sri Lanka, pp. 1422.
18. Awwad R, El Souki O, Jabbour M (2016) Construction safety practices and challenges in a Middle Eastern developing country. Safety science 83:1-11.

19. Mthalane D, Othman A, Pearl R (2008) The economic and social impacts of site accidents on South African society. Proceedings of the 5th Post Graduate Conference on Construction Industry Development, At Bloemfontein, South Africa.

20. Shah T (2005) Groundwater and human development: challenges and opportunities in livelihoods and environment. Water \& Science Technology 51(8): 27-37. IWA publishing.

21. Shah T, Molden D, Sakthivadivel R, Seckler D (2000) The global groundwater situation: overview of opportunities and challenges. Colombo, Sri Lanka: International Water Management Institute (IWMI) v, p.21.

22. Konikow LF, Kendy E (2005) Groundwater depletion: A global problem. Hydrogeology Journal 13(1): 317-320.

23. Knüppe $K$ (2011) The challenges facing sustainable and adaptive groundwater management in South Africa. Water SA, 37(1): 67-79.

24. Calow RC, Robins NS, MacDonald AM, Macdonald DMJ, Gibbs BR, et al. (1997) Groundwater management in drought prone areas of Africa. International Journal of Water Resources Development 13(2): 241- 261.

25. Kijewski-Correa T, Kareem A, Kochly M (2006) Experimental Verification and Full-Scale Deployment of Global Positioning Systems to Monitor the Dynamic Response of Tall Buildings. Journal of Structural Engineering 132: 8 (1242)

26. Frangopol DM, Liu M (2007) Maintenance and management of civil infrastructure based on condition, safety, optimization and life-cycle cost, Structure and Infrastructure Engineering 3(1): 29-41.

27. Rainieri C, Fabbrocino G, Cosenza E (2011) Integrated seismic early warning and structural health monitoring of critical civil infrastructures in seismically prone areas. Structural Health Monitoring 10(3): 291-308. 